\title{
Epistemic Communities and Epistemic Operating Mode
}

\author{
Marianna Y. Smirnova and Sergey Y. Yachin
}

\begin{abstract}
The article deals with the phenomenon of epistemic communities. The concept (and the term) was coined by $P$. Haas in the late $X X$ century in an attempt to analyze functions and political prospects of expert and professional knowledge in the modern knowledge-based society. The concept has been used widely during the recent decades in sociology of knowledge, policy studies and social philosophy. However, no (or very few) attempts to rethink the concept of epistemic communities have been made, despite some critical remarks. The article gives a review of research into epistemic communities and introduces the concept of epistemic mode in order to rethink the concept and make clear operational mechanisms of epistemic communities as a specific form of knowledge (expert) communities.
\end{abstract}

Index Terms-Epistemic communities, experts communities, epistemic mode, knowledge-based society.

\section{INTRODUCTION}

The concept of epistemic communities was developed by $\mathrm{P}$. Haas in the late XX century to explain how decision-makers and politicians interact with scientific and/or professional communities when challenged with global problems that require expert consulting. E. Haas and E. Adler also contributed to the concept formation.

The concept of epistemic communities suggests that these scientific and professional communities share ideas and resources to promote them (reputation, knowledge). Moreover, an epistemic community combines various characteristics: political initiative, scientific objectivity. This makes epistemic communities different from NGOs, advocacy coalitions, interest groups, etc. and gives them a special status.

The concept has been used widely during the recent decades in sociology of knowledge, policy studies and social philosophy, mainly in various case studies. The earliest attempts to sum up the research material date back to the first decade of the XX century. The current tendency to expand or even rethink the concept is relevant only for certain aspects, not for the concept as a whole. Some questions are still to be answered, namely, the question of defining epistemic communities' boundaries and limits of their independence, the mechanisms of their functioning, etc.

The article suggests the concept of «epistemic operating mode», which is intended to clear up the issue of defining borders of epistemic communities and eliminates some contradictions, which inevitably emerge when epistemic

Manuscript received April 20, 2014; revised June 25, 2014. This paper was supported by a grant of Far Eastern Federal University \#12-05-06-680-09/13

The authors are with the Far Eastern Federal University, School of Regional and International Studies (e-mail: marianna.y.smirnova@gmail.com, yachin@land.ru). communities are regarded as a permanent structure.

\section{THE FORMING OF THE EPISTEMIC COMMUNITY CONCEPT}

The concept of epistemic community in its current meaning was formed in the late XX century (the 90-s) by E. Haas, P. Haas and E. Adler. However, the idea that knowledge-based communities are of political importance was developed earlier, in the 70-s and 80-s.

The concept of epistemic community takes its origin in the "episteme" concept. The latter was widely used by $\mathrm{M}$. Foucault. In 1975, J. Ruggie introduced the term «epistemic community» with the reference to Foucault [1]. The concept grew more and more policy-oriented. However, in the 80-s the term «epistemic community» still had various interpretations.

E. Haas and P. Haas followed J. H. Marx and B. Holzner who defined epistemic communities as «those knowledge-oriented work communities in which cultural standards and social arrangements interpenetrate around a primary commitment to epistemic criteria in knowable production and application» [2].

E. Haas expanded this definition and included into the list of basic characteristics of epistemic communities adherence to certain values and political initiative. In 1989 P. Haas analyzed factors underlying the success of the so-called Mediterranean Plan. He found that it had succeeded due to engaging scientists, marine biologists and ecologists (members of an epistemic community) in the agenda forming [3].

Haas gave his own interpretation of the epistemic community concept in the «Introduction: Epistemic communities and International Policy Coordination» (1992).

Today, it is the most widely-recognized (and widely discussed) definition of epistemic communities [4]. According to it, epistemic communities have following features:

1) A shared set of normative and principled beliefs which provide a value-based rationale for the social action of community members;

2) Shared causal beliefs, which are derived from their analysis of practices leading or contributing to a central set of problems in their domain and which then serve as the basis for elucidating the multiples linkages between possible policy actions and desired outcomes;

3) Shared notions of validity - that is, intersubjective, internally defined criteria for weighting and validating knowledge in the domain of their expertise;

4) A common policy enterprise - that is, a set of common practices associated with a set of problems to which their professional competence is directed, presumably out of the conviction that human welfare will be enhanced as a 
consequence» [4].

Besides, P. Haas and E. Adler analyzed the role of epistemic communities in establishing a new world regime. Unlike some of their followers, Adler and Haas considered epistemic communities to be a kind of interpretative filter for political choices, not a new political actor.

Highly illustrative are two works by Haas and Adler, «Banning Chlorofluorocarbons: Epistemic Community Efforts to Protect Stratospheric Ozone» (1992) [5] and «The Emergence of Cooperation: National Epistemic Communities and the International Evolution of the Idea of Nuclear Arms Control» (1992) [6]. The first article presents research into activities of a transnational environmental epistemic community. It made a basis for the Montreal Protocol on Substances that Deplete the Ozone Layer. The second article analyzes how the idea of global nuclear disarmament evolved in the political interaction between the Soviet Union and the USA, which resulted in the Treaty on Anti-Ballistic Missile Systems in 1972. (This research was resumed and expanded by M. Dover in 2013 in an article on international cooperation

between the USA and the Russian Federation in the field of nuclear weapon non-proliferation in the last decade of the 20th century) [7].

Also, Haas and Adler made a hypothesis that epistemic communities are able to help establish a new alternative world regime without hegemons [8]. This theory can come true only under a number of conditions. The scholars made it clear that effectiveness and success of this alternative global regime depends on the extent in which it is based on shared values of the humanity, not individual states. It is self-evident that this is the highest goal to strive, which, however, cannot be achieved by formal procedures.

The above-mentioned works resulted in a commonly recognized and shared by numerous scholars' interpretation of epistemic community. S. Mendelson, T. Craig, A. Antoniades and others followed Haas when defining epistemic communities.

The concept has made its way into policy and social studies. But it is used mainly in case studies, predominantly in such fields as health (Z. Heritage, J. Green, and J. McGivern), environment protection (S. Murphy, K. Rosendal), economics (W. Drake, E. Karayannis), intellectual property (L. Dobush, S. Quak), etc. Works on Asia-Pacific are focused on regional security and economic development (J. Dosch, M. Mols), etc.

Z. Heritage and J. Green analyze activities of a transnational health epistemic community. According to the scholars, the community significantly contributed into the building of the European national networks «Health City» in 2003-2008 [9]. S. Sturdy, R. Freeman and J. Smith-Merry cover a wider chronological scope by studying activities of the World Health Organization from the 70-s to today [10].

The concept of epistemic communities also made a theoretical basis for an article by A. Balch's article on migration policy of Great Britain in the first decade of the 21 st century [11].

Informal links among epistemic communities' members contribute into consensus -building among decision-makers.

Not only do they provide expert knowledge, but also act as an intermediary. R. Tiller, T. Brekken, J. Baily highlight the intermediary function when analyzing political processes in integrated management of coastal aquacultures in Norway. Despite the fact that epistemic communities are underdeveloped there, the scholars hope that their emergence could prevent conflicts in this field [12]. However, it is difficult to measure how influential epistemic communities can be. D. J. Galbreath and J. McEvoy were challenged with this problem when trying to clear up the role of epistemic communities in the EU policy concerning minorities [13].

L. Dobush and S. Quack analyze the case of 《Creative Commons 》, a non-profit organization which addresses intellectual property issues [14]. They regard it as a politically successful epistemic community of lawyers. But their success is accounted to activities going far beyond the limits of an epistemic community. In fact, the 《Creative Common $\rangle$ : acted as a social movement because interpretative functions of epistemic communities were obviously insufficient.

It is to note that there are few attempts to theoretically expand or rethink the concept. Among them are ideas of $\mathrm{K}$. Bukhari, who, in search for theoretical foundations, pointed out that constructivism, with its vision of scientific knowledge as a socially constructed phenomenon, correlated with the epistemic community concept well [15]. But it was not a cover-all theoretical review.

Remarkable in this regard is the article by M. D. Cross «Rethinking epistemic communities twenty years later».

The article sums up the research into epistemic communities. According to Cross, the concept requires further conceptual development. Her own idea is that international epistemic communities should not be limited to scientific ones, that is, their knowledge should not be limited to scientific data [16].

M. Meyer and S. Molyneux-Hogson also reviewed and summed up existing variants of the concept. They pointed out that they do not explain how epistemic communities form and function [17].

Epistemic communities are currently under research. Interpretations of the phenomenon vary slightly, but most of the scholars follow Haas' definition and highlight two crucial features of epistemic communities: their political potential and shared knowledge and values of their members. The majority of works dedicated to epistemic communities are case studies which provide diverse examples but do not rethink or reinterpretate the concept itself (with some exceptions). However, the concept of epistemic communities needs refining (if not redefining).

\section{POLITICAL INDEPENDENCE OF EPISTEMIC COMMUNITIES: CRITICS AND DEBATES}

The concept of epistemic communities, despite its wide usage, provokes critics when applied to international policy coordination as its only explanation. J. Sebenius made some critical remarks to Haas' works in 1992 by pointing out that mechanisms of transforming values and ideas into political influence were not properly explained and cleared up [18]. Nearly a decade later A. Mooney and B. Evans voiced similar 
critics. They doubted that epistemic communities always have access to political agenda [19].

Epistemic communities cannot exist without direct links to politicians, and $\mathrm{P}$. Haas underlined this fact: epistemic communities are neither scientific nor political groups. That is why some scholars, for example, J. Peel, claim that institutionalization of epistemic communities is vitally important for their efficiency [20].

Of course, it is commonly accepted that the process of institutionalization can transform an epistemic community into some kind of interest group or advocacy coalition which acts to benefit governments or corporations. In this case no independence is possible.

Some scholars are much more optimistic, however. M. Sundstroem suggests that international epistemic communities can influence national experts so effectively that the latter develop a shared vision of current global problems and tend to arrive at an international conclusion easier [21].

Of much interest is D. Toke's critic of the epistemic community concept. He «accused» Haas of underestimating influence of interest groups [22]. K. Litfin and G. Kuetting provided some critics, too. Lift in analyzed the process of the Montreal Protocole in 1987 and admitted that scientists played an important role in developing political agreement. However, she pointed out that the epistemic communities approach simply underestimated how often scientific data were used just for the legitimization of current policy courses [23]. G. Kuetting claimed that Haas' statement that epistemic communities played the decisive role in forming the Mediterranean Plan has no foundations [24].

The above-described critics can make one think about how epistemic communities (knowledge) interact with decision makers (power) in general. Scholars have not arrived at an agreement in this question yet. Their opinions range from very optimistic to highly pessimistic. J. McGivern presented an example of an effective epistemic community without governmental support: the multidisciplinary biomedicine network «University Genetics Knowledge Park» made to transfer scientific data into the British health system. He tracked main parts of this process and described interaction between the epistemic community and other actors. Strictly speaking, the network was initiated by the government. But the latter failed to control it and cut the financing. In spite of this, the data provided by the experts found its way into the health system [25].

On the contrary, K. Dunlop described a totally different case by comparing two scientific groups which worked in the EU as two types of epistemic community. The groups addressed the issue of the growth hormone. One was government-initiated, the other formed evolutionally. Dunlop came to a conclusion that decision makers cannot delegate their power to an independent epistemic community, so they tend to establish their own communities by recruiting experts [26]. This conclusion undermines the idea of an independent and yet influential epistemic community. However, some researchers (for example, the above-mentioned Heritage and Green) regard governmentally initiated epistemic communities as normal and effective.
Sometimes scholars (M. King, for instance) regard epistemic communities' success as a result of mere coincidence of their goals with the goals of decision-makers [27].

\section{DEFINING Boundaries OF EPISTEMIC COMMUNITIES}

Especially difficult is the problem of defining boundaries or epistemic communities. They do not have a strict structure and, like an «invisible college», can include members of several organizations: scientists, researchers, politicians, officials, etc. However, no epistemic community can be fully integrated into governmental structures or corporations. Within an epistemic community only horizontal links can be effective. Any epistemic community, with its interdisciplinarity and absence of a formal leader, can be described as a network with a number of local "centers".

P. Haas was the first to try to differentiate between epistemic communities and other groups of the kind. He made up two schemes to illustrate the differences using two differentiating criteria: 1) shared causal beliefs; 2) knowledge basis of a certain type.

Epistemic communities are sometimes compared to policy communities or policy transfer networks (M. Evans, J. Davis), NGOs (J. Braithwaite, P. Drahos, K. Gough), discourse coalitions (K. Litfin), etc. It is quite obvious that all these groups and communities can be compared to epistemic ones from the standpoint of their functional and structural features. But they do not form the basis for epistemic communities. Expert groups do.

In the broad context of information society studies it is important to take into account the role of goal-setting subjects of knowledge (groups and individuals) in this society. The phenomenon of epistemic communities is connected with the process when scientists do not just serve the interests of economic and political actors but also try to solve global problems. Under these conditions, scientists do not just seek new knowledge and, consequently, the truth, which is the essence of scientific cognition. While considering the truth to be the highest value, they are also able to use their shared vision of the truth (knowledge) to address global political and economic issues.

The Pugwash Movement, which was founded in 1955 by a group prominent scientist, can serve as an example of such community. The Movement positions itself as a community of technical experts engaged in policy-oriented studies in the field of international security and arms control.

In the modern knowledge-based society it is crucial for scientists to understand which criteria can be used to justify their theories, because their object of cognition are not natural objects but technical/sociotechnical objects and developments.

Importantly and predictably, an emerging 《knowledge economy 》(or 《innovative economy》) results in increasing influence of scientists - bearers of domain-specific, predominantly scientific knowledge. The influence manifests itself in all social spheres: politics, culture, everyday life. As a rule, these recommendations are collective. In other words, they express a shared epistemic (knowledge-based) position 
of a certain scientific community.

The tendency to rely upon integrated expert knowledge for (predominantly) political and economic decision-making is a kind of modern innovation in itself. First of all, this tendency means that it s possible to integrate knowledge of various specialists (scientists) and obtain new knowledge which is shared by all scientists but does not belong to any scientist as an individual. That is why it is necessary to differentiate the competence of an individual expert, which is as old as human civilization, from the competence of an expert group, a community of specialists capable of proposing collective solutions. Special methods are required to obtain such shared knowledge. A popular method of polling scientist has been known since the 60th of the XX century under the name «Delphi method».

There is no reason to apply expert polls in highly specialized fields of knowledge which require experimental proof. Knowledge integration becomes useful when knowledge is a «direct productive force» and, when practically applied, leads to significant economic, political and social changes. That is why knowledge integration and expert evaluation are usually required at the conceptual (empirically non-verifiable) level and to forecast development of technical systems, weapons, climate changes, social institutions, on one hand, and develop scenarios of multi-level social subjects' actions, on the other.

Expert knowledge differs from classical scientific knowledge by its structure. It is required to use integrated expert knowledge to solve strategic economic and political problems. However, a paradox emerges: knowledge of physics, psychology, economics, etc. as separated fields of expertise looses its social (innovative) importance. Scientific knowledge becomes a political and economic power only in its systems, integrated and, to a great extent, interdisciplinary form.

Expert knowledge is differentiated from scientific knowledge by its subject. Whereas the latter studies real objects, while the expert knowledge deals with tendencies and foresight, which is non-existing or virtual objects. Therefore, expert knowledge is predominantly applicable to future scenarios developing (foresight).

The different ways of functioning of scientific and expert knowledge are the key to understanding the forming factors of expert communities, decision-making processes and politically or economically relevant recommendations, as well as to understanding the reason why any major organization - an industrial corporation, public authorities or international organizations like APEC - have to rely upon trust expert evaluations and form expert groups.

The answer to the question how modern expert communities (groups) are formed should be based upon historical retrospective. Epistemic communities are to be viewed as as a specific form of scientific community, because any cognitive activity is collective (meaning «live» knowledge exchange). The forming of increasingly broader scientific communities can be traced back to antiquity, when these communities were limited to scientific schools [4].

Later, professional communities (and universities) emerged. Expert communities emerged no earlier than in the $\mathrm{XX}$ century. It is not the final stage, though. Today expert communities can only be understood in the context of the forming of broader communities - epistemic ones.

This historical sequence can be imagined as building one integration level over another. Epistemic communities can be based on expert ones, being a higher level of their development to the extent in which they take human well-being into account.

However, one cannot say that an expert community ends where an epistemic one begins. Their similarities are not the only reason. The main reason is that any epistemic community is not an institution. It is a process of a kind, a state of mind which is enabled but a number of factors including human factor. An expert community can act as an epistemic one, which means, it is an epistemic community under current conditions.

\section{EPISTEMIC OPERATING MOde}

Epistemic communities do not have strict boundaries. On one hand, they can be regarded as a higher level of expert knowledge integration and development (compared to expert communities). But an epistemic community does not remain active forever. A. Antoniades divided epistemic communities into two categories: ad-hoc coalitions and permanent coalitions [28].

Any international expert (scientific) community can operate in different modes: as an interdisciplinary scientific community united by a common problem to solve; as an expert community given a task by some institution or government; as an epistemic community promoting its shared knowledge to help solve global problems. That is why research should be done into ways of epistemic communities' functioning, their operating mode.

In this article, it is suggested to regard any knowledge-based society from the standpoint of its specific operating mode which can be defined as epistemic operating mode.

Epistemic mode can be estimated with the help of a set of features given below:

1) Self-organization

Members of an "ideal" epistemic community act on their own initiative and cannot be recruited by governments or corporations to make their policy legitimate. However, grants or contracts do not make epistemic mode wholly impossible. Expert groups of international organizations or members of international projects can switch to the epistemic mode, being partly self-organizing.

2) Scientific truth as a shared value

No personal interest can be taken into account. Search for political compromise does not necessarily deny search for the truth. But it remarkably changes the operating mode of a community.

3) Personal position of any expert member of the community

This basically means that experts willingly take personal responsibility for their recommendations.

4) Adherence to shared values

A community working in the epistemic mode has a common system of values. On the contrary, a distinctly neutral (ethically) position of experts indicates that their 
community is not epistemic.

5) Political influence

Epistemic mode requires significant political influence which can be ensured by engaging decision-makers (politicians, investors).

6) Interdisciplinarity

In many cases, it ensures that projects under discussion can be realized. Therefore, high level of interdisciplinarity indicated epistemic mode. A strictly theoretical problem limited by a single discipline makes operating in this mode impossible.

7) Focus on global problems which affect human development, well-being and security

Such activities as foresight, scenarios of possible future variants are indicative. Epistemic communities seldom focus on solving problems which do not have any long-term consequences.

When most of these features are distinctly seen in the activity of a certain international scientific community, this community can be regarded as epistemic - which means, acting in the epistemic mode.

\section{CONCLUSION}

It is to note that any knowledge-based community can be characterized with the help of these criteria. They allow defining when and under what conditions it functioned in the epistemic mode. This approach explains or even eliminates many contradictions of existing concepts. They can also be used in developing measures to initiate epistemically functioning communities or switch existing expert groups into this mode.

\section{REFERENCES}

[1] J. Ruggie, Constructing the world polity: Essays on International Institutionalization, UK: Routledge, 1998.

[2] J. H. Marx and B. Holzner, Knowledge Application: the Knowledge System in Society, Allyn and Bacon, 1979.

[3] P. M. Haas, "Do regimes matter? Epistemic communities and Mediterranean pollution control," Knowledge, Power, and International Policy Coordination, vol. 43, no. 3, pp. 77-403, 1992.

[4] P. M. Haas, "Introduction: epistemic communities and international policy coordination," Knowledge, Power, and International Policy Coordination, vol. 43, no 3, pp. 1-35, 1992.

[5] E. Adler and P. M. Haas, "Banning chlorofluorocarbons: epistemic community efforts to protect stratospheric ozone," Knowledge, Power, and International Policy Coordination vol. 46, no. 1, pp. 187-224, 1992.

[6] E. Adler and P. M. Haas, "Conclusion: epistemic communities, world order, and the creation of a reflective research program," Knowledge. Power, and International Policy Coordination, vol. 46, no. 1, pp. 367-390, 1992.

[7] M. Dover, "Hard problems, soft answers: impact of epistemic communities on U.S. - Russian nuclear cooperation," dissertation, American University, 2013.

[8] E. Adler and P. M. Haas, "Conclusion: epistemic communities, world order, and the creation of a reflective research program," Knowledge, Power, and International Policy Coordination, vol. 46, no. 1, pp. 367-390, 1992.

[9] Z. Heritage and G. Green, "European national healthy city networks: the impact of an elite epistemic community," Journal of Urban Health, vol. 90 , no. 1, pp. 154-166, 2013.

[10] S. Sturdy, R. Freeman, and J. Smith-Merry, "Making knowledge for international policy: who Europe and mental health policy, 1970-2008," Social History of Medicine, vol. 26, no 3, pp. 532-554, 2013.

[11] A. Balch, "Labour and epistemic communities: the case of "managed migration' in the UK," The British Journal of Politics and International Relations, vol. 11, no. 4, pp. 613-633, 2009.

[12] R. Tiller, T. Brekken, and J. Bailey, "Norwegian aquaculture expansion and Integrated Coastal Zone Management (ICZM): Simmering conflicts and competing claims," Marine Policy, vol. 36, no. 5, pp. 1086-1095, 2012.

[13] D. J. Galbreath and J. McEvoy, "How epistemic communities drive international regimes: The case of minority rights in Europe," Journal of European Integration, vol. 35, no. 2, pp. 169-186, 2013.

[14] L. Dobusch and S. Quack, "Epistemic communities and social movements: transnational dynamics in the case of creative commons," in Transnational Communities: Shaping Global Economic Governance, UK: Cambridge University Press, 2010, pp. 226-252.

[15] K. Bukhari, "Constructivism and epistemic community: theoretical tools for understanding the crafting of foreign policy toward non-state actors," The McMaster Journal of Communication, vol. 1, no. 1, pp. 34-66, 2004

[16] D. M. Cross, "Rethinking epistemic communities twenty years later," Review of International Studies, vol. 39, no. 1, pp. 137-160, 2012.

[17] M. Meyer and S. M. Hogson. (2010). Introduction: The dynamics of epistemic communities. Sociological Research Online. [Online]. 15 Available: http://www.socresonline.org.uk/15/2/14.html

[18] J. Sebenius, "Challenging conventional explanations of international cooperation: Negotiation analysis and the case of epistemic communities," Knowledge, Power, and International Policy Coordination, vol. 46, no. 1, pp. 323-265, 1992.

[19] A. Mooney and B. Evans, Globalization: the Key Concepts, Taylor and Francis, 2007.

[20] J. Peel, Science and Risk Regulation in International Law, Cambridge University Press, 2010

[21] M. Sundstroem. (2000). A Brief Introduction: What is an Epistemic $\begin{array}{lll}\text { Community. } & \text { [Online]. Available: }\end{array}$ www.svet.lu.se/joluschema/epistcomm.pdf

[22] D. Toke, "Epistemic communities and environmental groups," Politics, vol. 19 , no. 2, pp. 97-102, 1999.

[23] K. Litfin, Ozone Discourses: Science and Politicsin Global Environmental Cooperation, Columbia University Press, 1994.

[24] G. Kuetting, Environment, Society and International Relations: Towards More Effective International Agreements, UK: Routledge, 2000.

[25] G. McGivern, "Inter-epistemic power and transforming knowledge objects in a biomedical network," Organization Studies, vol. 31, no. 12, pp. 1667-1686, 2010.

[26] C. Dunlop, "Epistemic communities, relational distance and the two goals of delegation: Hormone growth promoters in the European Union," Science and Public Policy, vol. 37, no. 3, pp. 205-217, 2010.

[27] M. King, "Epistemic communities and the diffusion of ideas: central bank reform in the United Kingdom," West European Politics, vol. 28, no. 1, pp. 94-123, 2005.

[28] A. Antoniades, "Epistemic communities, epistemes and the construction of (world) politics," Global Society, vol. 1, no. 1, pp 21-38, 2006

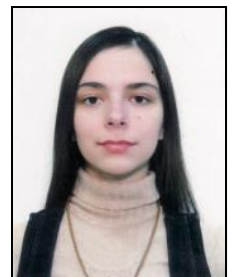

Marianna Y. Smirnova is an assistance lecturer at the department of liguistics and intercultural communication at the Far Eastern Federal University, School of Regional and International Studies, and a post-graduate student majoring in social philosophy. Her areas of research interest are methodology of social cognition and social processes in the knowledge-based society.

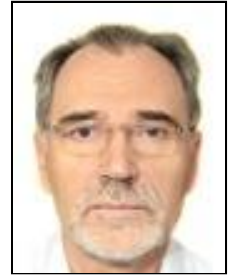

2008-2013.

Sergey Y. Yachin is a Ph.D. who obtained the degree in philosophy in 1975 and is currently the head of the department of philosophy at the Far Eastern Federal University, School of Humanities. His areas of research interest are methodology of social cognition and philosophical anthropology. S. Yachin is the author of more than 70 works including monographs and has been the head of a number of government-funded federal research projects in 